\title{
Dynamic analysis of a geared rotor-bearing system with translational motion due to shaft deformation under residual shaft bow effect
}

\author{
Ying-Chung Chen ${ }^{1,}$ a and Chun-Ku Kuo ${ }^{2}$ \\ ${ }^{1}$ Department of Aeronautical and Mechanical Engineering, Air Force Academy, Kaohsiung 820, Taiwan \\ ${ }^{2}$ Department of Mechanical Engineering, Air Force Institute of Technology, Kaohsiung 820, Taiwan
}

\begin{abstract}
In this paper, the dynamic response of a spur geared rotor-bearing system has been studied when the gear set has translational motion due to shaft deformation and residual shaft bow effect. A new dynamic model for the geared rotor-bearing system, considering translational motion and residual shaft bow effect, is proposed, in which the distance between the centers of two gears varies with time. Therefore, the proposed model regards gear pressure angle and contact ratio as time-varying variables, while the previous model regards them as constant. A finite element model of the geared rotor-bearing system developed, the equations of motion are obtained by applying Lagrange's equation. After deriving nonlinear equations of motion for the geared rotor-bearing system, the dynamic responses are computed by applying the fourth-order Runge-Kutta numerical method. The dynamic response including lateral response of two gears, gear pressure angle and contact ratio with different phase angle between two residual shafts are investigated. The results show that the magnitude of the residual shaft bow, the phase angle between two residual shafts will significantly affect gear pressure angle and contact ratio. This new model produces more accurate dynamic responses in comparison to those of the previous model.
\end{abstract}

\section{Introduction}

The geared rotor-bearing system is one of the main mechanisms for modern power transmission. It is often coupled with bearing systems, aviation generator, gas turbines, turbo-generators, power generation and power extraction. On account of the increasing demand for high speed and accurate transportation, the research in the field of geared rotor dynamics is very important. In practice, the shafts would deform after a certain period of service time. The dynamic analysis of the geared rotorbearing system with translational motion due to shaft deformation under residual shaft bow effect is investigated in this paper.

Lund [1] described a method for calculating the coupled torsional-lateral vibrations in a geared system of rotors. Nelson [2] studied effects of shear deformation and rotary inertia on rotor-bearing systems by utilizing the Timoshenko beam theory and finite element method. Kahraman et al. [3] developed a finite element model of a geared rotor system supported by flexible bearings. Shiau et al. [4] analyzed the coupled bending and torsional vibration of geared rotors as well as the effect of axial

\footnotetext{
${ }^{\text {a }}$ Corresponding author : ycchen80@gmail.com
} 
torque on bending vibrations. Lee et al. [5] developed the coupling of lateral and torsional vibration for the geared rotor-bearing system. The effect of residual shaft bow on the unbalance response of a single mass flexible rotor was investigated by Nicholas et al. [6]. Shiau and Lee [7] examined the dynamic response of a simply supported rotor under the effects of disk skew, unbalanced mass and residual shaft bow. The effect of the residual shaft bow on unbalance response of rotor-bearing system was investigated by Shiau et al. [8]. Kim et al. [9] analyzed the dynamic response of a spur gears by considering the pressure angle and the contact ratio as time-varying variables and a translational motion in the gear set due to bearing deformation. The effects of residual shaft bow and viscoelastic supports on dynamic response of a rotor-bearing system were investigated by Kang et al. [10]. Chen et al. [11] analyzed the interaction between gears, shafts and journal bearings in a geared rotor-bearing system. An optimization procedure for vibration reduction of a spur geared rotor-bearing system with residual shaft bow was investigated by Chen et al. [12].

\section{Modeling of the system}

The configuration of a geared rotor-bearing system is shown in Figure 1. Two uniform flexible shafts are of length $L_{1}$ and $L_{2}$. The residual bows of shaft 1 and 2 are $\delta_{r 1}$ and $\delta_{r 2}$. The gear pair is mounted on the shafts and an external torque $M$ exerts upon the driving gear. The contacting mesh force is represented by the gear mesh stiffness $k_{m}$ and damping $c_{m}$ along the pressure line. Four bearings are modeled as flexible elements with damping and stiffness denoted as $c_{j}^{b}$ and $k_{j}^{b}$. A single shaft system with a rigid disk is shown in Figure 2, in which the fixed reference frame, $X-Y-Z$, is used to describe the system motion. Five degrees of freedom $V, W, \alpha, \mathrm{B}, \Gamma$ are considered at each nodal point of the shaft, where $V$ and $W$ are lateral displacements along $Y$ and $Z$ directions, respectively, $\mathrm{B}$ and $\Gamma$ are rotational displacements, $\alpha$ is the torsional displacement, and the axial translational vibration is neglected. The displacement due to the residual shaft bow, shown in Figure 1 is assumed as a second-order polynomial [11]:

$$
\delta_{j}(s)=4 \delta_{r j} \frac{s}{L}\left(1-\frac{s}{L}\right), \quad j=1,2
$$

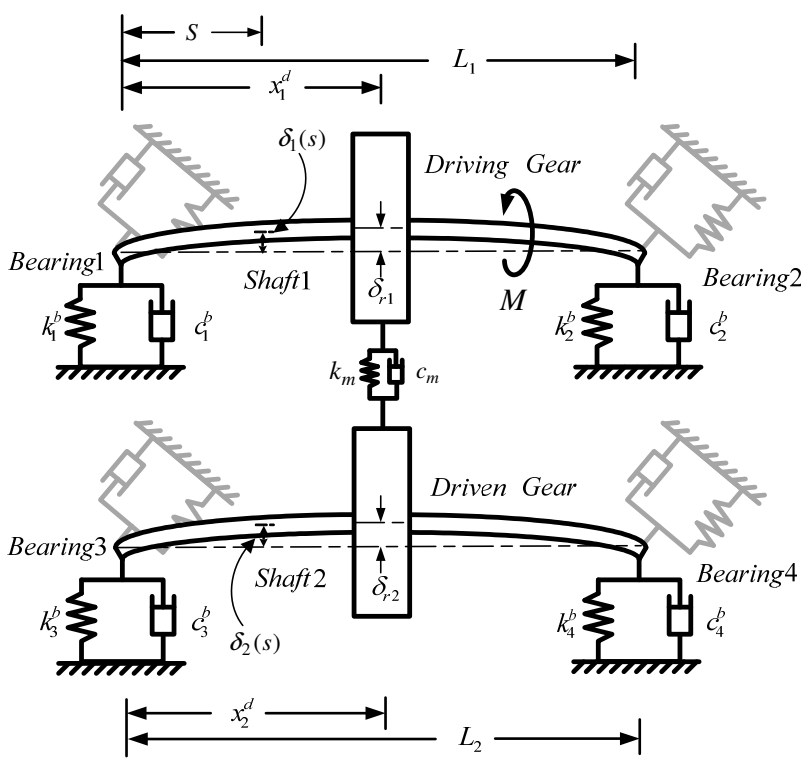

Figure 1. The configuration of a geared rotor-bearing system. 


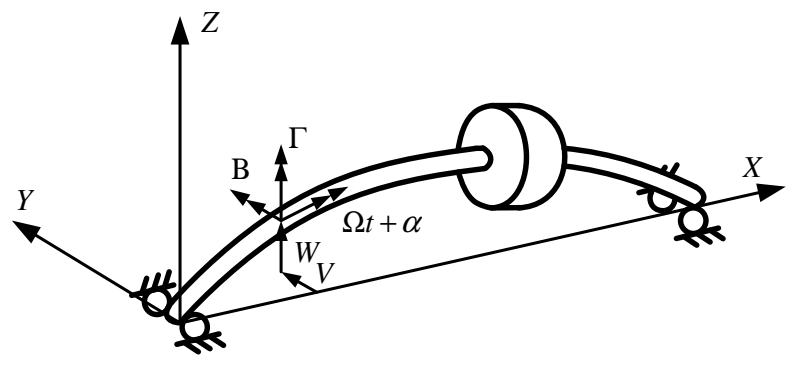

Figure 2. Typical rotor configuration and coordinates.

Figure 3 shows the configuration and generalized coordinates for the pair of gears [9], which are mounted on the shafts as shown in Figure1. The mass, transverse mass moment of inertia, polar mass moment of inertia of the driving gear and driven gear are, respectively, $m_{d 1}, I_{d D 1}, I_{d p 1}$, and $m_{d 2}, I_{d D 2}, I_{d p 2}$. The motion of the gear set can be defined with ten generalized coordinates, which are the same as the node coordinates of two shafts, where the gears are mounted. The dashed and solid circles represent the gear pair before and after motion, respectively. $O_{1}$ and $O_{2}$ are the initial centers of each shaft without residual bow. $O_{1}^{\prime}$ and $O_{2}^{\prime}$ are the centers under residual shaft bow effect. $C_{1}$ and $C_{2}$ are the axis centers after the motion. The mass centers of gears are denoted by $G_{1}$ and $G_{2}$. The magnitudes of the eccentricity are denoted by $e_{1}$ and $e_{2}$, and the eccentricity angles are denoted as $\Phi_{d 1}$ and $\Phi_{d 2}$. The angular coordinates of the driving and driven gears are defined as

$$
\theta_{i}(t)= \pm \Omega_{i} t+\alpha_{d i}(t)+\Phi_{d i}
$$

where $i=1$ and 2 mean the driving gear and driven gear, respectively. $\Omega_{i}$ is the spin speeds of shaft. The magnitudes of the residual shaft bow are denoted by $\delta_{r 1}$ and $\delta_{r 2}$, and the residual angles are denoted as $\Phi_{r 1}$ and $\Phi_{r 2}$. The angular coordinates of the driving and driven shafts are defined as

$$
\theta_{r i}(t)= \pm \Omega_{i} t+\alpha_{d i}(t)+\Phi_{r i}
$$

where $i=1$ and 2 mean the driving shaft and driven shaft, respectively. The displacement vectors for the mass centers of the gears are defined as

$$
\hat{r}_{i}(t)=\left[V_{d i}(t)+\delta_{r i} \cos \theta_{r i}+e_{i} \cos \theta_{\mathrm{i}}(t)\right] \hat{j}_{i}+\left[W_{d i}(t)+\delta_{r i} \sin \theta_{r i}+e_{i} \sin \theta_{\mathrm{i}}(t)\right] \hat{k}_{i}
$$

where $\hat{j}_{i}$ and $\hat{k}_{i}$ are the unit vectors in $X_{i}$ and $Y_{i}$ axes. The distance between centers, $d$, is changed to $d^{\prime}$ after the motion and residual shaft bow effect, and $d^{\prime}$ is defined as

$$
d^{\prime}(t)=\left\{\begin{array}{l}
{\left[V_{d 2}(t)-V_{d 1}(t)+d+\delta_{r 2} \cos \theta_{r 2}(t)-\delta_{r 1} \cos \theta_{r 1}(t)\right]^{2}} \\
+\left[W_{d 2}(t)-W_{d 1}(t)+\delta_{r 2} \sin \theta_{r 2}(t)-\delta_{r 1} \sin \theta_{r 1}(t)\right]^{2}
\end{array}\right\}^{0.5}
$$

In Figure 4, the gear pair is modeled as the equivalent stiffness $k_{m}$ and damping $c_{m}$ along the pressure line between the teeth. The equivalent stiffness is treated as time-varying coefficients in this paper. The pressure line is defined as the common tangent line of the base circles for the gear set, and the pressure angle $\phi_{p}$ is defined as 


$$
\phi_{p}(t)=\cos ^{-1}\left(\frac{R_{1}+R_{2}}{d^{\prime}(t)}\right)
$$

where $R_{1}$ and $R_{2}$ are the radii of base circles of gears. The angle of the driven gear relative to the driving gear is represented by

$$
\psi(t)=\tan ^{-1}\left(\frac{W_{d 2}-W_{d 1}+\delta_{r 2} \sin \theta_{r 2}-\delta_{r 1} \sin \theta_{r 1}}{V_{d 2}-V_{d 1}+d+\delta_{r 2} \cos \theta_{r 2}-\delta_{r 1} \cos \theta_{r 1}}\right)
$$

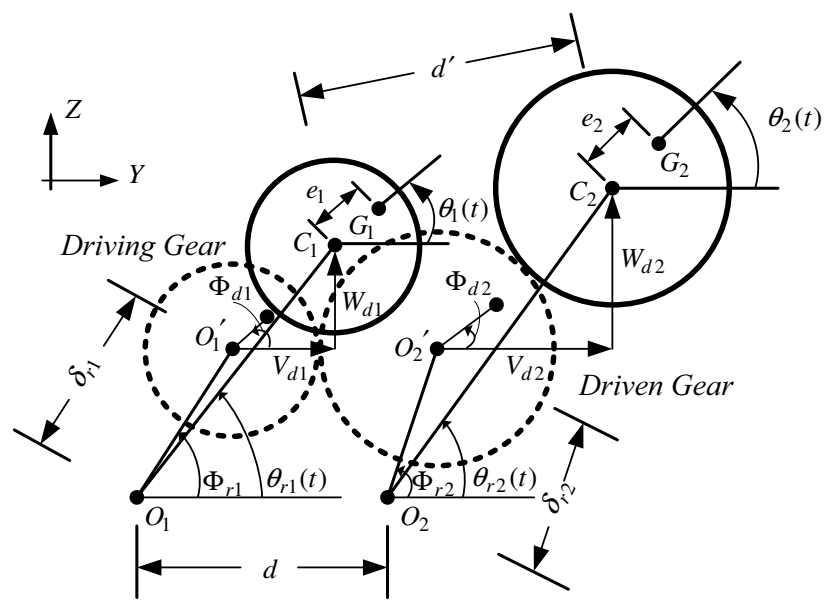

Figure 3. The configuration and generalized coordinates for gear pair.

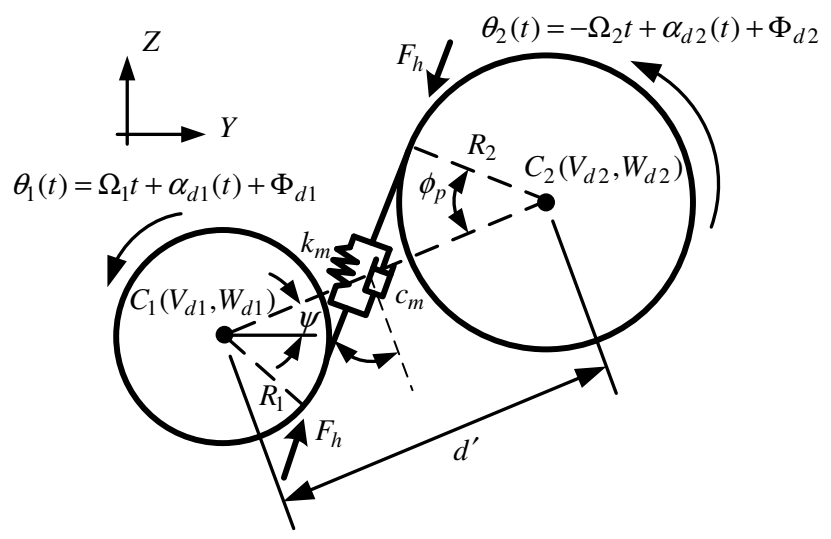

Figure 4. Gear mesh model of the gear pair.

The pressure angle and the gear position angle in this paper are affected by the translational motions of the gear pair and residual shaft bow effect while the previous studies neglected. According to the above assumption, the gear mesh is modeled as the equivalent stiffness and damping. The gear mesh deformation along the pressure line can be written as

$$
\begin{aligned}
\delta(t) & =\left(V_{d 2}-V_{d 1}+\delta_{r 2} \cos \theta_{r 2}-\delta_{r 1} \cos \theta_{r 1}\right) \sin \left(\phi_{p}-\psi\right) \\
& +\left(W_{d 2}-W_{d 1}+\delta_{r 2} \sin \theta_{r 2}-\delta_{r 1} \sin \theta_{r 1}\right) \cos \left(\phi_{p}-\psi\right)-\left(R_{1} \alpha_{d 1}+R_{2} \alpha_{d 2}\right)
\end{aligned}
$$


The gear mesh force along the pressure line can be expressed as

$$
F_{h}(t)=k_{m} \delta+c_{m} \dot{\delta}
$$

The mesh stiffness model in Kim et al. [9] is used in this paper, and is described as a periodic function with mesh period $T_{m}$ in Figure 5. The succeeding pair of teeth should contact immediately when one pair of teeth lose the contact with each other. The contact ratio $m_{p}$ is presented to measure this overlapping action. There are two pairs of contacting teeth when time $t$ is in the range from $(n-1) T_{m}$ to $\left(m_{p}+n-2\right) T_{m}$, and $k_{u}$ is the maximum mesh stiffness in this mesh process. There is only one pair of contacting teeth if $t$ is in the range from $\left(m_{p}+n-2\right) T_{m}$ to $n T_{m}$, and $k_{l}$ is the minimum mesh stiffness. The definition of $T_{m}$ and $m_{p}$ are defined as

$$
\begin{gathered}
T_{m}=\frac{2 \pi}{N_{1} \Omega_{1}}=\frac{2 \pi}{N_{2} \Omega_{2}} \\
m_{p}(t)=\frac{\sqrt{A_{1}^{2}-R_{1}^{2}}+\sqrt{A_{2}^{2}-R_{2}^{2}}-d \sin \phi_{p}(t)}{p_{b}}
\end{gathered}
$$

where $N_{1}$ and $N_{2}$ are the numbers of teeth for gears, $A_{1}$ and $A_{2}$ are the radii of the addendum circles, and $p_{b}$ is the base pitch.

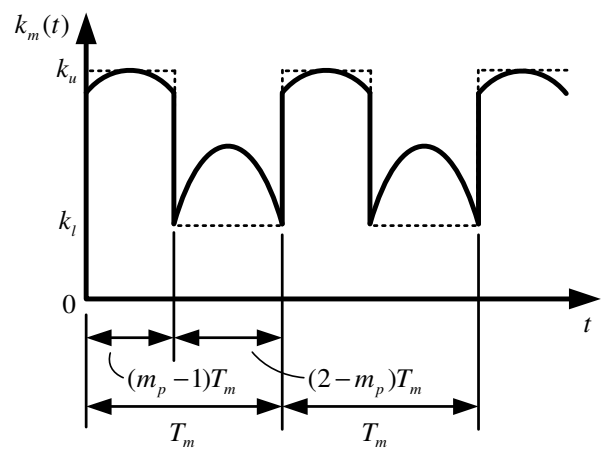

Figure 5. Gear mesh stiffness with the contact ratio $m_{p}$ and the mesh period $T_{m}$.

\section{Governing equation of the system}

The components of this geared rotor-bearing system include the gear pair, bearing supports and rotor shafts. The equations of motion are derived for each component as follows:

\subsection{Gear pair}

The gear pair in this paper is assumed as two rigid disks, so the kinetic energies of driving gear and driven gear can be described as

$$
T_{i}^{g}=\frac{m_{d i} \dot{\hat{r}}_{i}^{2}+I_{d p, i}\left( \pm \Omega_{i}+\dot{\alpha}_{d i}\right)^{2}+I_{d D, i} \dot{\mathrm{B}}_{d i}^{2}+I_{d D, i} \dot{\Gamma}_{d i}^{2}+I_{d p, i}\left( \pm \Omega_{i}+\dot{\alpha}_{d i}\right)\left(\dot{\mathrm{B}}_{d i} \Gamma_{d i}-\dot{\Gamma}_{d i} \mathrm{~B}_{d i}\right)}{2}
$$


The components of the gear mesh forces on the driving gear and the moment about the geometric center can be expressed

$$
\begin{gathered}
F_{h y 1}=-F_{h} \sin \left(\phi_{p}-\psi\right)=-\left(k_{m} \delta+c_{m} \dot{\delta}\right) \sin \left(\phi_{p}-\psi\right) \\
F_{h z 1}=-F_{h} \cos \left(\phi_{p}-\psi\right)=-\left(k_{m} \delta+c_{m} \dot{\delta}\right) \cos \left(\phi_{p}-\psi\right) \\
T_{h 1}=-R_{1} F_{h}=-R_{1}\left(k_{m} \delta+c_{m} \dot{\delta}\right)+M
\end{gathered}
$$

For the driven gears, similar expressions can be obtained. The corresponding equation of motion can be obtained as

$$
\left[\begin{array}{cc}
{\left[M_{1}^{g}\right]} & 0 \\
0 & {\left[M_{2}^{g}\right]}
\end{array}\right]\left\{\ddot{q}^{g}\right\}+\Omega_{1}\left[\begin{array}{cc}
{\left[G_{1}^{g}\right]} & 0 \\
0 & \frac{N_{t 1}}{N_{t 2}}\left[G_{2}^{g}\right]
\end{array}\right]\left\{\dot{q}^{g}\right\}+k_{m}\left[S_{h}\right]\left\{q^{g}\right\}=\left\{F^{g}\right\}
$$

where $\left\{q^{g}\right\}=\left\{\begin{array}{llllllllll}V_{g 1} & W_{g 1} & \mathrm{~B}_{g 1} & \Gamma_{g 1} & \alpha_{g 1} & V_{g 2} & W_{g 2} & \mathrm{~B}_{g 2} & \Gamma_{g 2} & \alpha_{g 2}\end{array}\right\}^{T},\left[M_{1}^{g}\right]$ and $\left[M_{2}^{g}\right]$ are mass matrices of driving gear and driven gear, $\left[G_{1}^{g}\right]$ and $\left[G_{2}^{g}\right]$ are gyroscopic matrices. The matrix $\left[S_{h}\right]$ is the stiffness term due to gear mesh effect. The vector $\left\{F^{g}\right\}$ is the force vector due to gear eccentricity and external torque.

\subsection{Shaft}

For shafts, two-noded element is used for the finite element formulation in this paper. As shown in Figure 6, five degrees of freedom are considered at each nodal point. The kinetic energy and potential energy of the shaft element can be expressed as

$$
\begin{gathered}
T^{e}=\frac{1}{2} \int_{0}^{l}\left\{\rho A\left(\dot{V}_{s}^{2}+\dot{W}_{s}^{2}\right)+I_{D}\left(\dot{\mathrm{B}}_{s}^{2}+\dot{\Gamma}_{s}^{2}\right)+I_{P}\left(\Omega_{i}+\dot{\alpha}_{s}\right)^{2}+I_{P}\left(\Omega_{i}+\dot{\alpha}_{s}\right)\left(\dot{\mathrm{B}}_{s} \Gamma_{s}-\dot{\Gamma}_{s} \mathrm{~B} s\right)\right\} d s \\
U^{e}=\frac{1}{2} \int_{0}^{l}\left\{E I_{D}\left[\left(\mathrm{~B}_{s}^{\prime}\right)^{2}+\left(\Gamma_{s}^{\prime}\right)^{2}\right]+G I_{P}\left(\alpha_{s}^{\prime}\right)^{2}+\kappa^{\prime} G A\left[\left(V_{s}^{\prime}-\Gamma_{s}\right)^{2}+\left(W_{s}^{\prime}+\mathrm{B}_{s}\right)^{2}\right]\right\} d s
\end{gathered}
$$

where $\rho, A, \kappa^{\prime}, I_{D}$ and $I_{p}$ are the mass density, cross-section area, shear factor for the circular cross-section, transverse mass moment of inertia and polar mass moment of inertia for the shaft, respectively. $E, G$ are the Young's modulus and shear modulus of the shaft. By using the Lagrangian approach, the motion equations of a shaft element can be obtained as:

$$
\left(\left[M^{e}\right]+\left[M^{r}\right]\right)\left\{\ddot{q}^{e}\right\}+\Omega\left(\left[G^{e}\right]+\left[G^{r}\right]\right)\left\{\dot{q}^{e}\right\}+\left(\left[K^{e}\right]+\left[K^{r}\right]\right)\left\{q^{e}\right\}=\left\{F^{r}\right\}
$$

where $\left\{q^{e}\right\}=\left\{\begin{array}{llllllllll}V_{e 1} & W_{e 1} & \mathrm{~B}_{e 1} & \Gamma_{e 1} & \alpha_{e 1} & V_{e 2} & W_{e 2} & \mathrm{~B}_{e 2} & \Gamma_{e 2} & \alpha_{e 2}\end{array}\right\}^{T},\left[M^{e}\right],\left[G^{e}\right]$ and $\left[K^{e}\right]$ are mass, gyroscopic and stiffness matrices of the shaft element, respectively; $\left[M^{r}\right],\left[G^{r}\right],\left[K^{r}\right]$ and $\left\{F^{r}\right\}$ are mass, gyroscopic, stiffness matrices and forcing vector due to the residual shaft bow, respectively. The details are given in Shiau et al. [8].

\subsection{Bearing}

In this paper, four bearing supports are assumed as isotropic. The potential energy and virtual work of $j$ th bearing support can be expressed as 


$$
U_{j}^{b}=\frac{k_{j}^{b} V_{b j}^{2}+k_{j}^{b} W_{b j}^{2}}{2} \text { and } \delta W_{j}^{n c}=-c_{j}^{b} \dot{V}_{b j} \delta V_{b j}-c_{j}^{b} \dot{W}_{b j} \delta W_{b j}
$$

By using the Lagrangian approach, the motion equations of $j$ th bearing support can be obtained as

$$
\left[\begin{array}{cc}
c_{j}^{b} & 0 \\
0 & c_{j}^{b}
\end{array}\right]\left\{\dot{q}_{j}^{b}\right\}+\left[\begin{array}{cc}
k_{j}^{b} & 0 \\
0 & k_{j}^{b}
\end{array}\right]\left\{q_{j}^{b}\right\}=\left\{\begin{array}{l}
0 \\
0
\end{array}\right\}
$$

where $\left\{q_{j}^{b}\right\}=\left\{\begin{array}{ll}V_{b j} & W_{b j}\end{array}\right\}^{T}$ and $j=1 \sim 4$.

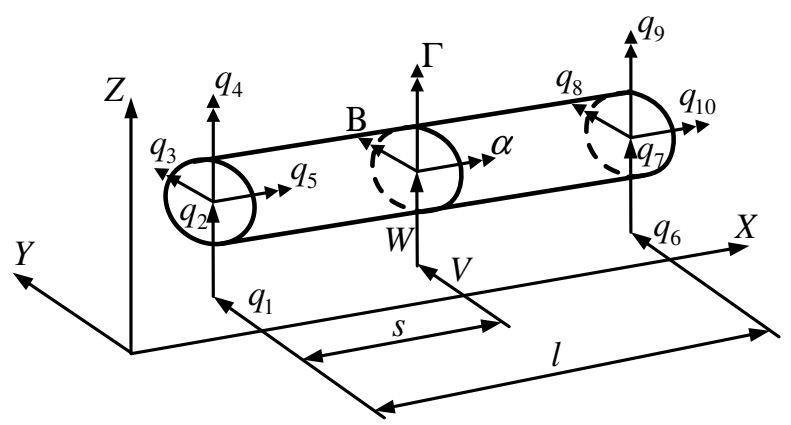

Figure 6. Shaft element and coordinate system.

\subsection{System equation of motion}

The system equation of motion is obtained by assembling equations of each component of the system, and can be expressed as:

$$
\left[M^{s}\right]\left\{\ddot{q}^{s}\right\}+\left(\Omega\left[G^{s}\right]+\left[C^{s}\right]\right)\left\{\dot{q}^{s}\right\}+\left[K^{s}\right]\left\{q^{s}\right\}=\left\{F^{s}\right\}
$$

where $\left\{q^{s}\right\}$ is the state vector, $\left[M^{s}\right],\left[G^{s}\right],\left[C^{s}\right]$ and $\left[K^{s}\right]$ are the mass, gyroscopic, damping and stiffness matrices of the system, respectively. $\left\{F^{s}\right\}$ is the forcing vector due to gear mesh, external torque, gear eccentricity and residual shaft bow effect.

Table 1. Parameters of the spur gear pair.

\begin{tabular}{|l|c|c|}
\hline & Driving gear & Driven gear \\
\hline Number of teeth & $N_{1}=20$ & $N_{2}=30$ \\
\hline Base circle radius [mm] & $R_{1}=18.8$ & $R_{2}=28.2$ \\
\hline Addendum circle radius [mm] & $A_{1}=22$ & $A_{2}=32$ \\
\hline Mass [g] & $m_{1}=78.4$ & $m_{2}=176.5$ \\
\hline Mass moment of inertia [kg-m $\left.{ }^{2}\right]$ & $1.39 \times 10^{-5}$ & $7.01 \times 10^{-5}$ \\
\hline Eccentricity angle[degree] & $\Phi_{d 1}=0$ & $\Phi_{d 2}=0$ \\
\hline Gear mesh damping coefficient [N-sec/m] & \multicolumn{2}{|c|}{$c_{m}=1.8$} \\
\hline Mesh stiffness during one-pair contact [N/m] & \multicolumn{2}{|c|}{$k_{l}=0.75 \times 10^{8}$} \\
\hline Mesh stiffness during two-pair contact [N/m] & \multicolumn{2}{|c|}{$k_{u}=1.25 \times 10^{8}$} \\
\hline
\end{tabular}




\section{Results and discussion}

In this section numerical simulations are performed for a geared rotor-bearing system. The parameters of the spur gear pair and rotor-bearing system are shown in Table 1 and Table 2, which are referred to Kim et al. [9] and Chen et al. [12], respectively. The nonlinear gear mesh stiffness shows in Figure 5 are considered and $\Omega_{1}$ is selected as $3000(\mathrm{rpm})$. The radius of two shaft are the same and equal to $r_{s 1}=r_{s 2}=0.0185(\mathrm{~m})$, the residual angles of two shaft are the same and equal to $\Phi_{r 1}=\Phi_{r 2}=0$. The external torque $M$ is selected as $45(\mathrm{~N}-\mathrm{m})$. Figure 7 shows the lateral responses of driving gear and driven gear with different magnitudes of residual shaft bow. It is seen that the lateral response increases as the magnitude of residual shaft bow increases.

Table 2. Parameters of the rotor-bearing system.

\begin{tabular}{|l|c|}
\hline Shaft length $[\mathrm{mm}]$ & $L_{1}=L_{1}=254$ \\
\hline Gear pair position $[\mathrm{mm}]$ & $x_{1}^{d}=x_{2}^{d}=L_{1} / 2$ \\
\hline Shaft density $\left[\mathrm{kg} / \mathrm{m}^{3}\right]$ & $\rho=7800$ \\
\hline Young's modulus $\left[\mathrm{N} / \mathrm{m}^{2}\right]$ & $E=2.07 \times 10^{11}$ \\
\hline Shear modulus $\left[\mathrm{N} / \mathrm{m}^{2}\right]$ & $G=8.28 \times 10^{10}$ \\
\hline Poisson ratio & $v=0.25$ \\
\hline Bearing damping coefficient $[\mathrm{N}-\mathrm{sec} / \mathrm{m}]$ & $c_{y y}=c_{z z}=1 \times 10^{3}$ \\
\hline Bearing stiffness $[\mathrm{N} / \mathrm{m}]$ & $k_{y y}=k_{z z}=1 \times 10^{8}$ \\
\hline
\end{tabular}

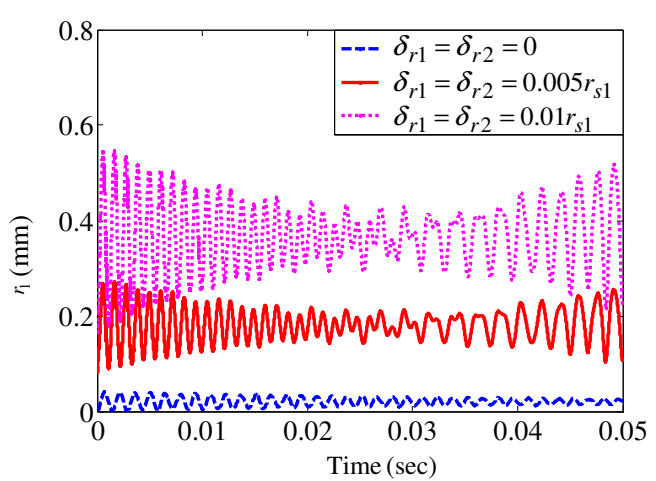

(a) lateral response of driving gear

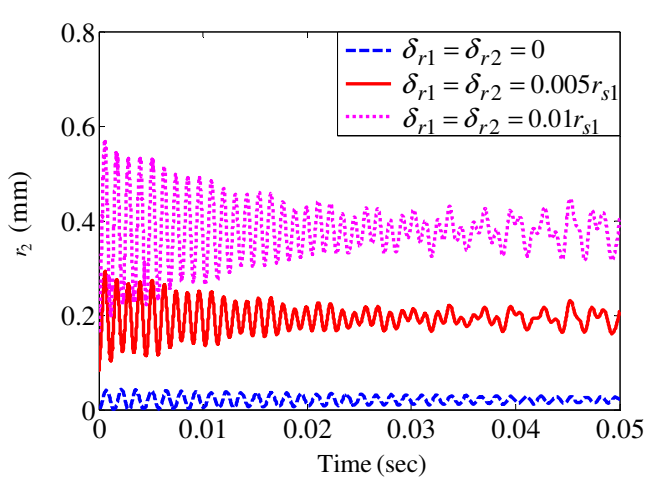

(b) lateral response of driven gear

Figure 7. Lateral response of driving gear and driven gear with different magnitudes of residual shaft bow.

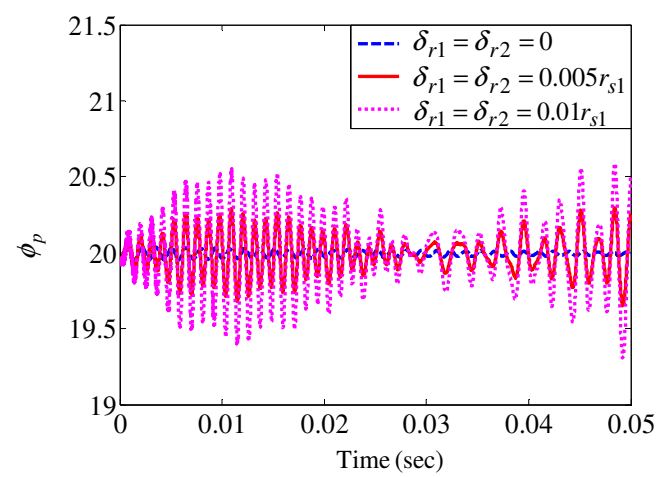

(a) gear pressure angle

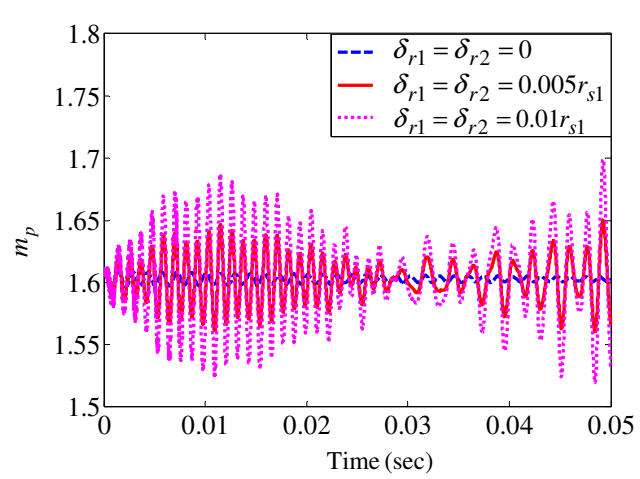

(b) gear contact ratio

Figure 8. Gear pressure angle and contact ratio with different magnitudes of residual shaft bow. 
Gear pressure angle and contact ratio with different magnitudes of residual shaft bow are shown in Figure 8. With residual shaft bow increases, gear pressure angle and contact ratio enhance. The effect of residual shaft bow would be significant and should not be ignored while $\delta_{r 1}$ and $\delta_{r 2}$ were large enough.

Figure 9 and Figure 10 show gear pressure angle and contact ratio with different external forces and magnitudes of residual shaft bow. In this section the external torque $M$ is selected as 10 and $45(\mathrm{~N}-$ $\mathrm{m})$. When the external force is higher, the effect of residual shaft bow on gear pressure angle and contact ratio will be enlarged.

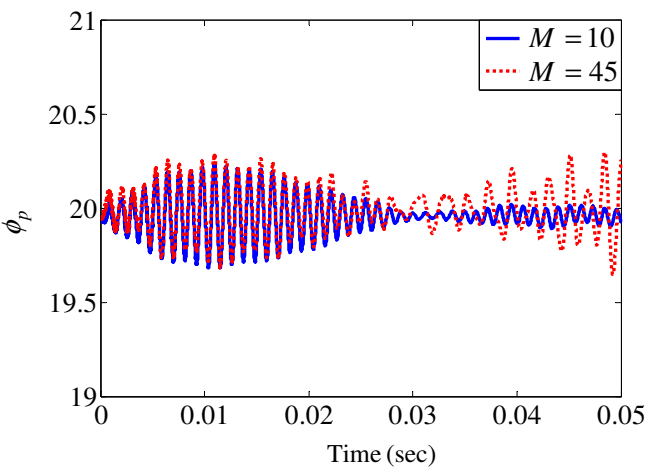

(a) $\delta_{r 1}=\delta_{r 2}=0.005 r_{s 1}$

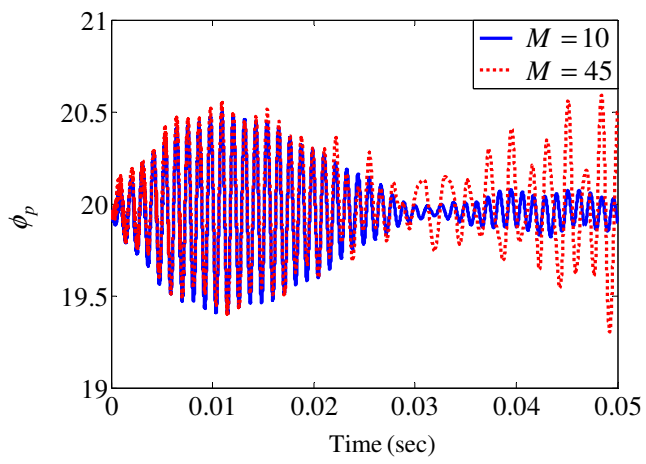

(b) $\delta_{r 1}=\delta_{r 2}=0.01 r_{s 1}$

Figure 9. Gear pressure angle with different external force and magnitudes of residual shaft bow.

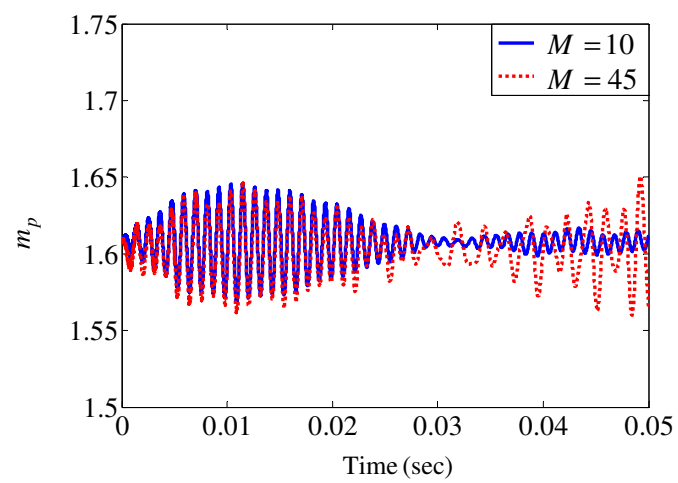

(a) $\delta_{r 1}=\delta_{r 2}=0.005 r_{s 1}$

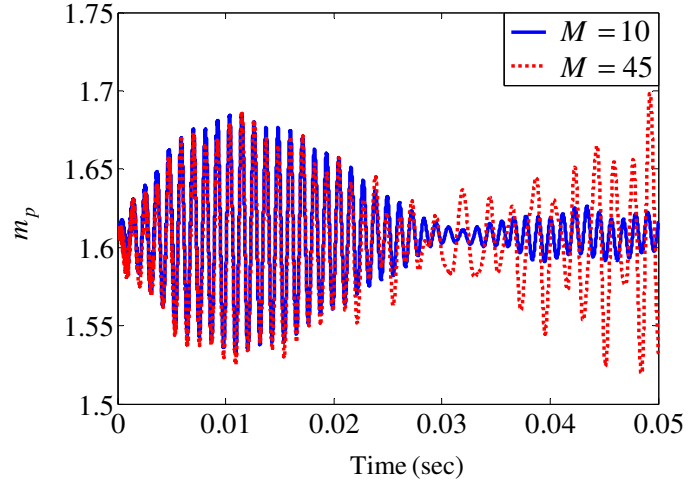

(b) $\delta_{r 1}=\delta_{r 2}=0.01 r_{s 1}$

Figure 10. Gear contact ratio with different external force and magnitudes of residual shaft bow.

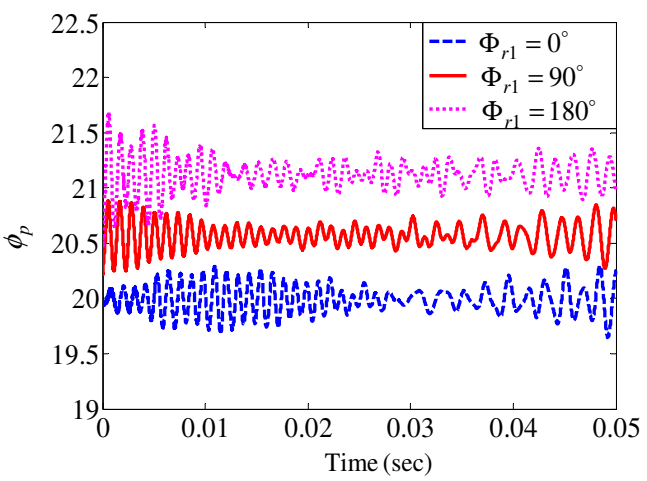

(a) gear pressure angle

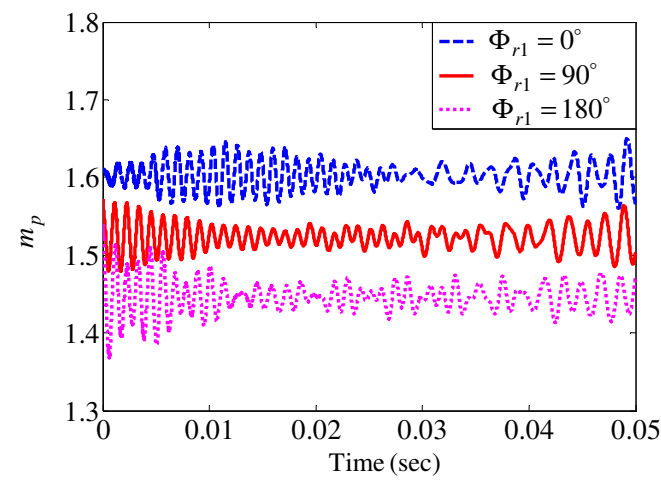

(b) gear contact ratio

Figure 11. Gear pressure angle and contact ratio with different residual angles of shaft 1 . 
In the followings, the residual shaft bow is considered for $\delta_{r 1}=\delta_{r 2}=0.005 r_{s 1}$, the residual angle of shaft 2 is still selected as $\Phi_{r 2}=0$. Gear pressure angle and contact ratio with different residual angles of shaft 1 are shown in Figure 11. Gear pressure angle is increased when the residual angle of shaft 1 is increased. Gear contact ratio is reduced when the residual angle of shaft 1 is increased. It means that residual angle significantly affects gear pressure angle and contact ratio.

\section{Conclusions}

This paper investigates a new dynamic model for spur geared rotor-bearing system which is considering translational motion and residual shaft bow effect. This new model which is deficient in the previous researches produces more accurate dynamic responses in comparison to those of the previous model. Based on the equations of motion, the dynamic responses were computed by applying the fourth-order Runge-Kutta numerical method. With residual shaft bow increases, lateral response, gear pressure angle and contact ratio enhance. With higher external force, the effect of residual shaft bow on gear pressure angle and contact ratio will be enlarged. Residual angle significantly affects the gear pressure angle and contact ratio. The effect of residual shaft bow would be significant and should not be ignored when the residual shaft bow was large enough.

\section{References}

1. J. W. Lund, J. Mech. Des., 100, 535-538 (1978)

2. H. D. Nelson, J. Mech. Des. 102, 793-803 (1980)

3. A. Kahraman, H. N. Ozguven, D. R. Houser, and J. J. Zakrajsek, J. Mech. Des., 114, 507-514 (1992)

4. T. N. Shiau, S. T. Choi, and J. R. Chang, Mech. Mach. Theory, 33, 761-783 (1998)

5. A. S. Lee, J. W. Ha, and D. H. Choi, J. Sound Vibr., 263, 725-742 (2003)

6. J. C. Nicholas, E. J. Gunter, and P. E. Allaire, J. Eng. Power., 98, 171-181 (1976)

7. T. N. Shiau, and E. K. Lee, J. Vib. Acoust., 111, 170-178 (1989)

8. T. N. Shiau, E. K. Lee, and Y. C. Chen, IGTI GT2006-90435 (2006)

9. W. Kim, H. H. Yoo, and J. C. Hung, J. Sound Vibr., 329, 4409-4421 (2010)

10. C. H. Kang, W. C. Hsu, E. K. Lee, and T. N. Shiau, Mech. Mach. Theory, 46, 264-275 (2011)

11. Y. C. Chen, C. H. Kang, and S. T. Choi, J. Vibroeng., 14, 1141-1150 (2012)

12. Y. C. Chen, C. H. Kang, and S. T. Choi, J. Chin. Soc. Mech. Eng., 36, 471-480 (2015) 